\title{
ACESSO LEXICAL E PRODUÇÃO DE FALA BILÍNGUE: O PROCESSO DE SELEÇÃO LINGUÍSTICA
}

\author{
Elena Ortiz Preuss ${ }^{1}$
}

\begin{abstract}
This article ${ }^{2}$ presents the results of an investigation of the production of bilingual speech, in which interlingual interference effects in the speech of bilinguals Portuguese-Spanish and Spanish-Portuguese were analyzed. The materials, designed within the picture-word interference paradigm, language interference (semantic, phonological/ orthographic and identity) and cognate (cognates, not cognates and false cognates) effects were manipulated. The results provide evidence for the languagespecific selection hypothesis (Costa et.al., 1999), since the naming latencies was faster in the related condition, in contexts involving language identity and phonological/ orthographic facilitation effects, as well as in the unrelated condition, when contexts involved semantic interference effects. Furthermore, the cognate status of words played an important role in the process of lexicalization, a fact that needs to be further assessed.
\end{abstract}

Key-words: lexical selection, bilingual speech, interference effects, cognate effect.

1 Professora da Faculdade de Letras da Universidade Federal de Goiás - UFG, Campus Goiânia.

2 Neste artigo consta uma versão parcial da pesquisa desenvolvida para a minha tese de doutorado, sob a orientação da Profa. Dra. Ingrid Finger, pelo programa de Pós-Graduação em Letras da UFRGS.

Organon, Porto Alegre, nº 51, julho-dezembro, 2011, p. 81-101 


\section{INTRODUÇÃO}

O fato de os bilíngues conseguirem manter a comunicação em somente uma de suas línguas, de forma rápida e eficaz, pode dar a entender que o processo de produção de fala bilíngue é simples. Porém, a frequente ocorrência de interferências ${ }^{3}$ entre as línguas é um indício da complexidade subjacente a esse contexto de produção de fala. Além disso, muitas pesquisas têm evidenciado que as duas línguas do bilíngue permanecem ativadas no momento da produção de fala e que o nível de ativação dos nós lexicais ${ }^{4}$ relacionados ao conceito-alvo desempenham um papel importante no resultado desse processo (cf. COSTA, 2005, 2006; GREEN, 1998; entre outros).

Nesse contexto, vários pesquisadores têm se dedicado a compreender como se desenvolve a produção de fala bilíngue. Mais especificamente, interessa-lhes saber que tipo de mecanismo garante a produção na língua-alvo, isto é, como são selecionadas palavras de uma das línguas somente, para concretizar a comunicação. A esse respeito, duas hipóteses sobre a seleção são constatadas: a Hipótese de Seleção Específica na língua (doravante HSE), segundo a qual, o mecanismo de seleção lexical só é sensível ao nível de ativação dos nós lexicais da língua de resposta (COSTA, MIOZZO \& CARAMAZZA, 1999); e a Hipótese de Seleção Não-Específica na língua (doravante HSNE), supondo que a seleção lexical é sensível ao nível de ativação de todos os nós lexicais, independente da língua a que pertençam, por isso é necessário um mecanismo de controle para garantir que a produção se concretize na língua pretendida (HERMANS, BONGAERTS, DE BOT \& SCHREUDER, 1998). Ao longo dos anos houve pesquisas, cujos resultados deram sustentação a cada uma dessas hipóteses, o que revela a necessidade de mais estudos, a fim de se chegar a conclusões mais confiáveis e que permitam contribuir para uma melhor compreensão desse processo.

3 Usou-se o termo "interferências", neste contexto específico, para abranger a ideia de transferência negativa, cujo produto pode constituir-se numa expressão inadequada, em outras palavras, quando a produção não ocorre somente numa das línguas, devido à presença de empréstimos linguísticos, codeswitching e erros de fala.

4 Em consonância com a afirmação de Costa (2005) de que o acesso no nível lexical permite alcançar todas as propriedades da palavra (gênero, morfologia...), entendemos que um nó lexical é a combinação de propriedades gramaticais e semânticas de um item lexical (palavra). 
Nosso estudo, portanto, visa a contribuir com um melhor entendimento sobre a produção de fala bilíngue, uma vez que pretende: i) observar se há evidências sobre a especificidade da seleção ou de competição entre as línguas, no processo de seleção lexical; ii) observar como os tempos de reação de resposta dos participantes é afetado pelos seguintes efeitos de interferência: semântica (semantic interference effect), identidade interlinguística (cross-language identity effect) e facilitação fonológica/ ortográfica (orthographic/ phonological facilitation effect); iii) investigar se há evidências de efeito cognato na produção de fala, através da manipulação de palavras cognatas, não cognatas e falsos cognatos no experimento.

A partir dos estudos desenvolvidos por Hermans, Bongaerts, De Bot \& Schreuder (1998), Costa, Miozzo \& Caramazza (1999) e Costa \& Caramazza (1999), desenvolvemos um experimento, dentro do paradigma de interferência desenho-palavra, aplicado a um grupo de bilíngues espanhol-português e português-espanhol. Os participantes tinham que nomear desenhos na sua L2, enquanto ignoravam as palavras distratoras que apareciam na L1. Com vistas a alcançar nossos objetivos, houve manipulação das relações entre desenho e palavra de modo a permitir observar os efeitos de interferência (semântica, de identidade, fonológica) e o efeito cognato.

Este artigo está estruturado da seguinte maneira: primeiro fazemos uma breve discussão teórica sobre acesso lexical e produção de fala bilíngue. Em seguida, descrevemos os procedimentos metodológicos adotados na pesquisa. Posteriormente, expomos as análises e discussões dos resultados. Depois, apresentamos as considerações finais, seguidas pelas referências.

\section{ACESSO LEXICAL E PRODUÇÃO DE FALA BILÍNGUE}

É amplamente consensual a ideia de que o processo de produção de fala tem início no primeiro nível de representação, conhecido como conceptual (ou semântico), com a ativação da representação semântica do conceito-alvo, que espalha ativação proporcional às representações de conceitos semanticamente relacionados. Por exemplo, junto com a ativação do conceito-alvo "cachorro", também são ativados outros conceitos relacionados, como, "gato", "latir", etc. A seguir, a ativação concei-

Organon, Porto Alegre, nº 51, julho-dezembro, 2011, p. 81-101 
tual flui e se espalha pelo segundo nível de representação, o lexical, ativando proporcionalmente os nós lexicais ou palavras correspondentes. Nesse momento, o sistema dispõe de várias palavras para a produção e deve decidir qual nó lexical será escolhido para o processamento. Após a seleção do nó lexical, o próximo passo da produção de fala ocorre no terceiro nível de representação, o fonológico, com a recuperação dos segmentos fonológicos correspondentes (COSTA, 2005, 2006). Entretanto, no contexto bilíngue, esse processo apresenta alguns pontos obscuros, quais sejam: 1) Quanto à estrutura e organização do nível conceptual, é preciso saber se é único para todas as línguas (compartilhado) ou se cada língua gera um sistema conceptual diferente (isolado); 2) Quanto ao funcionamento do mecanismo de seleção no nível lexical, é preciso saber se é específico na língua de resposta ou se é sensível ao nível de ativação das duas línguas e, por isso, precise de procedimentos de controle inibitório da língua não-alvo; 3) Quanto à fluidez da ativação no nível fonológico, é necessário saber se é restrita ao nó lexical-alvo ou espalhada, e se é afetada pela ativação das outras palavras não-alvo (COSTA, 2005). Além disso, Costa (2005) explica que, em termos de produção de fala bilíngue, ainda é necessário compreender melhor as implicações da existência de representações lexicais em línguas diferentes no bilíngue e como o falante se desloca através dos níveis de representação.

De Bot (1992) foi um dos especialistas que tratou de esboçar um modelo de produção de fala bilíngue, a partir de uma adaptação do modelo de fala de Levelt (1989), que tentou explicar o processo de fala em língua materna. De Bot (1992) explica que se baseou no modelo de fala de Levelt (op.cit.) ${ }^{5}$, devido a sua sólida base empírica e por ser incremental e em paralelo ${ }^{6}$, e só fez as mudanças consideradas extremamente necessárias para o contexto bilíngue. A primeira modificação proposta por De Bot (op.cit.) está relacionada com a descrição do conceptualizador como específico na língua, uma vez que a mensagem preverbal contém tanto as intenções do falante como a informação sobre a lín-

5 Conforme o modelo de Levelt (1989) a construção da mensagem verbal envolve processos linguísticos e conceituais através dos seguintes componentes: conceptualizador (que seleciona e ordena a informação conceitual relevante), formulador (responsável por estruturar formalmente a mensagem e gerar um plano de fala) e articulador (que converte o plano de fala em fala real).

6 É incremental, pois se desenvolve progressivamente entre os componentes e é em paralelo, em virtude da simultaneidade dos processos, ou seja, enquanto há intenções do falante sendo processadas no conceptualizador, outras já foram processadas e estão prontas para serem articuladas. 
gua a ser usada na produção. A partir das especificações da mensagem preverbal, a língua específica é ativada no formulador, encarregado de estruturar o plano de fala. $\mathrm{O}$ formulador é específico na língua, uma vez que as línguas podem aplicar diferentes procedimentos de codificação fonológica e gramatical. Em seguida, o plano de fala é enviado ao articulador que não é específico na língua, pois armazena todos os sons possíveis e padrões prosódicos das línguas. Com esse modelo, De Bot (op.cit.), baseado nas ideias de Green (1986), tenta explicar também a ocorrência de codeswitching pela formulação paralela de dois planos de fala simultaneamente. Um para a língua-alvo e outro para a outra língua ativada, o que facilitaria a interação entre as línguas.

Poulisse \& Bongaerts (1994) descrevem a proposta de De Bot (1992) como contraditória e não-econômica, porque prevê a escolha da língua na mensagem preverbal, mas propõe a formulação de dois planos de fala em paralelo. Os pesquisadores (op.cit.), também baseados em Levelt (1989) defendem que a escolha da língua ocorre na mensagem preverbal e, a partir disso, o falante bilíngue gerencia os sistemas linguísticos. Assim, não é necessário o planejamento simultâneo nas duas línguas para a produção de fala, pois o processo de seleção lexical se espalha pelos diferentes níveis de representação.

La Heij (2005) também defende que a mensagem preverbal contém todas as informações necessárias para a produção, mas há pesquisadores que não acreditam que isso seja suficiente para garantir a produção na língua pretendida e, por isso, defendem outros mecanismos de controle. Roelofs (1998) e Levelt et. al. (1999) defendem a ideia de que um procedimento de checagem estabelece se há correspondência adequada entre o nó do lema ativado e o nó do conceito lexical ativo. Mas para Green (1998), esse procedimento necessita mais refinamento para garantir que o nó selecionado seja realmente o pretendido para a produção. Conforme seu modelo de controle inibitório (inhibitory control, doravante CI), a intenção de produzir uma palavra numa determinada língua deve ser parte da representação conceitual, e essa deve selecionar os lemas relevantes. Cada lema tem uma etiqueta (tag), associada à L1 e à L2, e esse rótulo afeta a ativação do lema, pois também é parte da representação conceitual. $\mathrm{O}$ autor (op.cit.) propõe um mecanismo de supressão de lemas com rótulo incorreto (por exemplo, por interferências da língua não-alvo), para garantir a produção na língua pretendida. Em

Organon, Porto Alegre, n⿳⺈ 51, julho-dezembro, 2011, p. 81-101 
outras palavras, conforme o modelo CI, os bilíngues controlam seus sistemas linguísticos através de mecanismos de controle que inibem reativamente potenciais competidores na produção de fala.

Segundo Costa (2005), no modelo de Green (1998), a seleção lexical poderia ser executada sem processo inibitório, pois o conceito lexical é específico na língua. Costa (op.cit.) explica que a lexicalização começa com a ativação do conceito lexical, que ativa o nó lexical correspondente, e que a seleção lexical depende de procedimentos de checagem que verificam a compatibilidade entre o nó lexical ativo e o conceito lexical pretendido. Mas o autor (op.cit.) ressalta que os processos inibitórios também podem ser importantes na produção da fala bilíngue, principalmente, nos estágios iniciais de aquisição. Presume-se que em estágios mais avançados o mecanismo de seleção específica da língua esteja plenamente funcional. A seguir aprofundaremos mais a discussão sobre a especificidade linguística do mecanismo de seleção lexical.

\section{O processo de seleção lexical na produção de fala bilíngue}

Conforme exposto anteriormente, o funcionamento do mecanismo de seleção lexical, no caso bilíngue, ainda não é bem compreendido. Há teóricos defendendo que a seleção é um processo competitivo, inclusive, entre itens lexicais de línguas diferentes, e há outros defendendo que a seleção pode ser específica na língua (COSTA, 2005, 2006). A esse respeito, encontra-se na literatura duas hipóteses de seleção. Segundo a HSNE (Hipótese da Seleção Não-Específica na língua - Language-Nonspecific Selection hypothesis), todos os nós competem para a seleção, pois o mecanismo é sensível ao nível de ativação de todos os nós lexicais, independente da língua a que pertençam. Nesse caso, a facilidade da seleção do nó lexical pretendido vai depender amplamente do nível de ativação de todas as palavras, e, supostamente, o nó lexical com maior nível de ativação é o alvo (HERMANS, BONGAERTS, DE BOT \& SCHREUDER, 1998). Mas para a HSE (Hipótese da Seleção Específica na língua - Language-specific Selection Hypothesis), o mecanismo de seleção lexical não é sensível ao nível de ativação dos nós lexicais da língua de não-resposta, ou seja, somente são candidatos à seleção os nós lexicais da língua de resposta (COSTA, MIOZZO \& CARAMAZZA, 1999).

Consoante com a HSNE, destacamos o modelo de controle inibitório, o qual defende a existência de um mecanismo inibitório, encarregado de suprimir ou inibir a ativação de nós lexicais que não pertençam à 
língua-alvo (GREEN, 1998). Assim, mesmo que nós lexicais da língua de não-resposta sejam ativados, o mecanismo inibitório fará a supressão da ativação dos nós que não correspondam ao alvo, o que garante que a seleção lexical corresponderá a palavra-alvo na língua pretendida. Isso equivale a dizer que a seleção lexical não é específica na língua e que há grande possibilidade de interferência entre as línguas.

Hermans, Bongaerts, De Bot \& Schreuder (1998) desenvolveram dois experimentos de interferência desenho-palavra para verificar se há interferência da L1 durante o processo de acesso lexical na L2. Falantes nativos de holandês foram instruídos a nomear desenhos em sua língua estrangeira, inglês, enquanto ignoravam estímulos de interferência apresentados visual ou auditivamente. Os dados evidenciaram a presença de efeito de facilitação fonológica, e que o nome do desenho em holandês é ativado durante os primeiros estágios do processo de lexicalização em inglês como língua estrangeira. Esses resultados foram tomados como evidência de que a ativação fluente não é específica na língua, e que a seleção lexical também considera os níveis de ativação das palavras da língua não-alvo. Tais constatações foram tomadas com evidências em favor da HSNE.

Por outro lado, Levelt, Roelofs \& Mayer (1999) propuseram um mecanismo de checagem que confere a correspondência entre o nó do lema ativado e o nó do conceito lexical ativo, e, assim, assegura que a palavra selecionada é compatível com o significado pretendido pelo falante. Roelofs (1998) estendeu essa proposta para o caso bilíngue, em consonância com a HSE, defendendo que esse mecanismo é sensível a ambas as línguas do bilíngue. Se não há compatibilidade entre a língua da palavra selecionada e a língua pretendida, o mecanismo de checagem detecta a incompatibilidade e o nó lexical ativado é ignorado, antes mesmo de ser processado. Desta forma, garante-se que somente o nó lexical da língua-alvo será eventualmente produzido, e não haveria interferência entre as línguas.

Costa, Miozzo \& Caramazza (1999), com o objetivo de verificar a especificidade linguística da seleção lexical, realizaram uma série de experimentos com bilíngues catalão-espanhol. Ao combinar pares de desenho-palavra na mesma língua (catalão-catalão) ou em línguas diferentes (catalão-espanhol), foram investigados os efeitos de facilitação de identidade (quando a palavra distratora corresponde ao nome do desenho ou à sua tradução), facilitação semântica (quando a palavra Organon, Porto Alegre, nº 51, julho-dezembro, 2011, p. 81-101 
distratora é uma palavra semanticamente relacionada ao nome do desenho) e facilitação fonológica (quando a distratora é uma palavra relacionada fonologicamente). A partir dos resultados, foi possível constatar evidências de efeitos de identidade, principalmente, entre pares na mesma língua. Também foram observados efeitos de interferência semântica parecidos entre distratoras ${ }^{7}$ em catalão e em espanhol, bem como facilitação fonológica na nomeação, com pares na mesma língua, mas não entre línguas diferentes. Para esses pesquisadores (op.cit.), tais resultados fortalecem a HSE, mas argumentam que a incongruência dos mesmos e aqueles obtidos por Hermans et. al. (op.cit.) pode ter ocorrido em virtude de diferença no nível de proficiência dos participantes (mais ou menos equilibrados) e/ou demanda da tarefa, quanto à língua escolhida para a resposta (L1 ou L2)

Ainda com relação às contradições dos resultados dos dois experimentos anteriormente descritos, Costa \& Caramazza (1999) sugerem que talvez o mecanismo específico não seja funcional em estágios iniciais de aquisição de L2, e que a competição lexical não precisa ser, exclusivamente, entre as línguas, mas talvez entre lemas da mesma língua. Além disso, ponderaram que os resultados de Costa, Miozzo \& Caramazza (1999) podem ter sua origem no tipo de tarefa (nomear na L1, em vez da L2), no grau de similaridade entre as línguas envolvidas, e/ou nos diferentes tipos de bilíngues. Em vista disso, realizaram dois novos experimentos com dois grupos de bilíngues, inglês-espanhol e espanhol-inglês, que foram solicitados a nomear desenhos em sua L1 (primeiro grupo) ou em sua L2 (segundo grupo), enquanto ignoravam palavras distratoras na L1 ou na L2. Os resultados dos dois experimentos evidenciaram que a nomeação era mais rápida quando desenho e distratora correspondiam à mesma palavra (condição de identidade), principalmente, com distratoras na mesma língua. Observou-se que a nomeação era lenta quando o desenho e a palavra eram semanticamente relacionados, tanto entre pares na mesma língua quanto em línguas diferentes, o que é evidência de efeitos de interferência semântica. Assim, novamente os resultados serviram para fortalecer a HSE.

De acordo com os estudos anteriormente descritos, há evidências em favor de cada uma das hipóteses sobre a seleção lexical. Isso revela

7 Ao longo deste artigo, por razões estilísticas, o adjetivo “distratora” (ou seu plural “distratoras”) poderá aparecer sozinho ou acompanhando seu substantivo de referência que é "palavra" (ou "palavras"). 
a necessidade de mais pesquisas, com o objetivo de esclarecer melhor esse processo. Assim, a seguir, descrevemos um estudo que visa a contribuir para a compreensão do processo de produção de fala bilíngue.

\section{PROCEDIMENTOS METODOLÓGICOS}

\section{Natureza do estudo}

Nossa pesquisa se inscreve dentro do paradigma de interferência desenho-palavra que permite manipular a natureza das relações entre desenho e palavra distratora, e, a partir dos tempos de reação de resposta, analisar o processo de seleção lexical (COSTA, 2005; 2006). Esse paradigma possibilita observar os seguintes efeitos:

1) Interferência semântica: quando, na condição relacionada, o desenho e a palavra distratora pertencem à mesma categoria semântica (cachorro e gato, por exemplo). Nesse contexto, a nomeação será lenta, pois a distratora proporciona ativação extra, o que acaba interferindo na seleção do alvo (HERMANS et. al., op.cit.).

2) Identidade interlinguística: quando, na condição relacionada, a palavra distratora corresponde à tradução do nome do desenho (condição de identidade). Nesse caso, cada uma das hipóteses de seleção, descritas anteriormente, supõe algo distinto. Para a HSE, a nomeação será rápida na condição de identidade, pois só será examinado o léxico da língua de resposta (COSTA, MIOZZO \& CARAMAZZA, 1999; COSTA \& CARAMAZZA, 1999). Mas para a HSNE, ambos léxicos serão examinados, uma vez que o mecanismo de seleção é sensível à ativação dos dois léxicos ativados, por isso a nomeação será lenta na condição de identidade (HERMANS, BONGAERTS, DE BOT \& SCHREUDER, 1998).

3) Facilitação fonológica/ortográfica: é um tipo de efeito de identidade mediado fonologicamente ou ortograficamente e corresponde ao contexto em que, na condição relacionada, a palavra distratora possui similaridade fonológica ou ortográfica com o nome do desenho. Nessa circunstância, espera-se nomeação mais rápida das palavras cognatas do que as não-cognatas.

Organon, Porto Alegre, nº 51, julho-dezembro, 2011, p. 81-101 
As expectativas descritas nos itens 1 e 3 constituem-se em hipóteses do nosso trabalho, exatamente como foram expostas ${ }^{8}$. Mas no que se refere ao item 2, seguimos os pressupostos da HSE. Além disso, cabe ressaltar que o efeito cognato não foi observado só no caso da facilitação (descrito acima, no item 3), mas interrelacionado com os outros efeitos de interferência (semântica e de identidade).

\section{Participantes}

Os experimentos foram realizados por 23 bilíngues equilibrados ${ }^{9}$, sendo 13 bilíngues espanhol-português e 10 bilíngues português-espanhol. Os participantes residiam numa região de fronteira seca entre Brasil e Uruguai, abrangendo as cidades de Santana do Livramento (Brasil) e Rivera (Uruguai). A idade média dos participantes era de 38 anos e todos eles afirmaram usar frequentemente a sua L2.

\section{Experimento e procedimentos}

Todos os participantes tiveram que responder a um questionário e realizar uma prova de proficiência, a fim de melhor caracterizá-los. Para os bilíngues português-espanhol foi aplicada uma prova de proficiência, adaptada do DELE (Diplomas de Espanhol como Lengua Extranjera), nível superior. Para os bilíngues espanhol-português, a prova aplicada foi adaptada do CILP (Certificado Internacional de Língua Portuguesa $)^{10}$, também de nível superior.

Nas tarefas propriamente ditas, os participantes tinham que dizer o mais rápida e corretamente possível o nome do desenho na L2, enquanto ignoravam as palavras distratoras que apareciam em sua $\mathrm{L} 1^{11}$. Foram desenvolvidas duas tarefas, uma para os bilíngues espanhol-português e outra para os bilíngues português-espanhol, mas seguindo as mesmas características experimentais, ou seja, tinham o mesmo design. Os testes

8 Ressalta-se que as duas hipóteses sobre a seleção (HSE e HSNE) só fazem diferentes previsões no efeito de identidade interlinguistica.

9 Trata-se de uma amostra de conveniência, pois refere-se a bilíngues equilibrados adultos, que aceitaram participar voluntariamente da pesquisa e que realizaram todas as etapas de coleta de dados. 10 O CILP é oferecido pelo Programa de Português para Estrangeiros, da UCS (Universidade de Caxias do Sul). Queremos registrar nossos agradecimentos a Profa Valneide Luciane Azpiroz por nos disponibilizar esse material.

11 Essa opção por nomear na L2 foi motivada pelas considerações de Costa \& Caramazza (1999), expostas anteriormente, sobre as incongruências dos resultados de Costa et. al. (1999) e de Hermans et. al. (1998), e em defesa da HSE. 
tinham a seguinte sequência: primeiro aparecia uma tela com o ponto de fixação (por 300ms), em seguida aparecia a palavra distratora na L1 (por 300ms) e por último aparecia a tela com o desenho, que permanecia aberta até o participante iniciar a nomeação do desenho, desde que isso não ultrapassasse o tempo de $4000 \mathrm{~ms}$, pois, nesse caso, o programa avançava automaticamente para a próxima sequência. Salienta-se que o início das respostas dos participantes era captado por um microfone ligado a uma caixa de resposta $(S R B O X)$ que registrava os tempos de reação. A figura seguinte ilustra a nossa descrição:

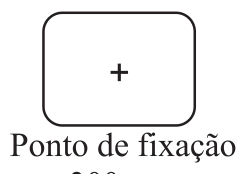

$300 \mathrm{~ms}$

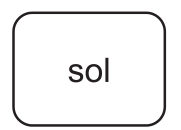

Palavra na L1

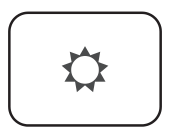

Desenho até $4000 \mathrm{~ms}$

Figura 1: Design das tarefas

As palavras que compuseram os instrumentos foram controladas em termos de frequência e extensão. Cada tarefa envolvia 190 pares de desenho-palavra, sendo que os dez primeiros pares serviam para que os participantes praticassem e se familiarizassem com os testes, não sendo, portanto, considerados para fins de análise. Os demais pares (180) foram distribuídos conforme o quadro abaixo:

\begin{tabular}{lcc}
\hline \multicolumn{1}{c}{ EFEITOS } & $\begin{array}{c}\text { CONDIÇÃO } \\
\text { RELACIONADA }\end{array}$ & CONDIÇÃO NÄ0-RELACIONADA \\
\hline Interferência semântica com cognatas & 10 & 10 \\
\hline Interferência semântica com não cognatas & 10 & 10 \\
\hline Interferência semântica com falso-cognatas & 10 & 10 \\
\hline Identidade interlinguística com cognatas & 10 & 10 \\
\hline Identidade interlinguística com não cognatas & 10 & 10 \\
\hline Identidade interlinguística com falso-cognatas & 10 & 10 \\
\hline Facilitação fonológica/ortográfica com cognatas & 10 & 10 \\
\hline Facilitação fonológica/ortográfica com não cognatas & 10 & 10 \\
\hline Facilitacão fonológica/ortográfica com falso-cognatas & 10 & 10 \\
\hline Total de pares de palavras & $\mathbf{9 0}$ & $\mathbf{9 0}$ \\
\hline
\end{tabular}

Quadro 1: Síntese das condições testadas e número de palavras no experimento

Para exemplificar melhor, elaboramos um quadro, baseado nos testes para bilíngues espanhol-português, no qual citamos os pares de desenho-palavra, nas diferentes condições testadas.

Organon, Porto Alegre, nº 51, julho-dezembro, 2011, p. 81-101 


\begin{tabular}{cccccc}
\hline $\begin{array}{c}\text { TIPO DE EFEITO DE } \\
\text { INTERFERÊNCIA }\end{array}$ & $\begin{array}{c}\text { TIPO DE } \\
\text { PALAVRA }\end{array}$ & DESENHO PRODUÇÃO-ALVO PALAVRA DISTRATORA & $\begin{array}{c}\text { PALAVRA } \\
\text { RELACIONADA }\end{array}$ & $\begin{array}{c}\text { PISTRATORA } \\
\text { NÃ0-RELACIONADA }\end{array}$ \\
\hline Semântica & Cognata & León & Leão & Gato & Cspejo \\
& NãoCognata & Poroto & Feijão & Chaucha & Zueco \\
& Falso-cognato & Pelota & Bola & Globo & Humo \\
Identidade & Cognata & Abeja & Abelha & Abeja & Queso \\
Interlinguística & Não Cognata & Pavo & Peru & Pavo & Codo \\
& Falso-cognato & Cinta & Fita & Cinta & Oficina \\
Facilitação & Cognata & Barco & Barco & Barba & Oro \\
fonológica/ & Não Cognata & Sandia & Melancia & Mecedor & Chancho \\
Ortográfica & Falso-cognato & Hueso & Osso & Oso & Pelota \\
\hline
\end{tabular}

Quadro 2: Exemplos de pares de palavras

No quadro 2, expusemos o desenho e a produção esperada, para evidenciar as relações fonológicas envolvidas (ou não) em cada caso. Como se percebe, no caso da interferência semântica, a distratora relacionada é da mesma categoria semântica que o nome do desenho; no efeito de identidade, a distratora relacionada corresponde a tradução do nome do desenho na L1; e no efeito de facilitação há mais compartilhamento de segmentos fonológicos entre o nome do desenho na L2 e a distratora relacionada. A palavras distratoras não-relacionadas, funcionam como condição de controle e não compartilham significado, nem segmentos fonológicos com o correspondente nome do desenho na L2.

\section{Análise dos dados}

Com a ajuda dos componentes do software E-prime, os dados foram fundidos, filtrados e salvos em planilhas que permitiram exportá-los para serem analisados estatisticamente (através do software SPSS), em termos de variância (ANOVA) e comparação de médias (Teste T). As análises estatísticas envolveram: a) comparações entre os tipos de efeitos de interferência testados (semântica $\mathrm{x}$ de identidade $\mathrm{x}$ fonológica); b) comparações entre os tipos de palavras (cognatas $\mathrm{x}$ não-cognatas $\mathrm{x}$ falso-cognatas); c) comparações entre os tipos de condição de relação (relacionada x não-relacionada); d) interações entre os tipos de efeitos de interferência e os tipos de palavras; e) interações entre os tipos de efeitos de interferência e os tipos de condição de relação; e f) interações entre os tipos de palavras e os tipos de condição de relação.

Para fins de análise, foram consideradas somente as respostas que denominamos corretas. Dentre as respostas classificadas como incorretas e 
que foram excluídas das análises, constavam: 1) respostas que não correspondiam ao nome do desenho na L2; 2) falhas de gravação; e 3) disfluências verbais (produção de sons não-verbais que acionavam a chave de voz, reparos de fala e gagueira, por exemplo). Também foram excluídas as respostas iniciadas com menos de $300 \mathrm{~ms}^{12}$ e com mais de $4000 \mathrm{~ms}^{13}$.

\section{DISCUSSÃO DOS RESULTADOS}

Faremos a discussão dos resultados a partir da descrição da Figura 2, na qual constam a média dos tempos de reação (TR) e o desvio padrão (DP) em cada condição (relacionada - CR e não-relacionada CNR), nos diferentes tipos de interferência (semântica - IS, identidade - II, fonológica - FFO), e com os diferentes tipos de palavras (cognatas, não-cognatas e falso-cognatas).

\begin{tabular}{|c|c|c|c|c|c|c|c|}
\hline & & \multicolumn{2}{|c|}{ IS } & \multicolumn{2}{|c|}{ II } & \multicolumn{2}{|c|}{$\mathrm{FFO}$} \\
\hline & & $C R$ & CNR & $C R$ & CNR & $C R$ & CNR \\
\hline \multirow[t]{2}{*}{ Cognatas } & Média - TR & 1134,19 & 1118,13 & 886,11 & 1129,9 & 1102,50 & 1141,83 \\
\hline & DP & 249,86 & 258,64 & 248,83 & 293,83 & 255,33 & 251,55 \\
\hline \multirow{2}{*}{$\begin{array}{c}\text { Não- } \\
\text { Cognatas }\end{array}$} & Média - TR & 1491,95 & 1395,2 & 1481,26 & 1507,79 & 1334,20 & 1414,10 \\
\hline & $D P$ & 301,31 & 284,67 & 314,25 & 295,53 & 287,96 & 277,92 \\
\hline \multirow{2}{*}{$\begin{array}{c}\text { Falso- } \\
\text { Cognatas }\end{array}$} & Média - TR & 1289,86 & 1255,87 & 1325,80 & 1400,97 & 1246,02 & 1400,74 \\
\hline & DP & 277,53 & 300,44 & 299,91 & 313,92 & 332,64 & 259,47 \\
\hline
\end{tabular}

Figura 2: Média dos tempos de reação (TR) e desvio padrão (DP)

Conforme ilustra a Figura 2, percebe-se que a nomeação foi mais lenta na condição relacionada, no caso do efeito de interferência semântica e mais rápida, nessa mesma condição de relação, no caso dos efeitos de identidade interlinguística e de facilitação fonológica/ortográfica. Após submetermos esses resultados às análises estatísticas, constatamos que foram significativas: a comparação entre as condições relacionada e

12 Para alguns pesquisadores, as pessoas demoram em média $200 \mathrm{~ms}$ para acessar o léxico mental e produzir uma palavra, mas, no nosso estudo, como se tratava da L2, e considerando algumas médias de tempos de resposta de estudos com L2, consideramos 300ms um tempo mínimo adequado (cf. COSTA, 2010)

13 Esse índice é mais alto do que o que é normalmente adotado em pesquisas (3000ms em média), mas, considerando que a média de idade dos participantes era um pouco alta (38 anos), julgamos prudente estabelecer um limite maior para o início das nomeações, porque há evidências empíricas de que a idade afeta a latência de nomeação.

Organon, Porto Alegre, n⿳⺈ 51, julho-dezembro, 2011, p. 81-101 
não-relacionada $(\mathrm{F}(1,22)=6,87, \mathrm{MSE}=41515,69, \mathrm{p}<, 05)$ e $(\mathrm{t}(22)=-2,62$, $\mathrm{p}<, 05)$; a interação entre tipos de interferência e os tipos de condição de relação (relacionada - não-relacionada) $(\mathrm{F}(2,44)=6,80, \mathrm{MSE}=39847,02$, $\mathrm{p}<, 05)$; e entre os tipos de interferência e as condições relacionada e nãorelacionada, nas comparações das médias de tempo de reação, envolvendo o efeito facilitação fonológica/ortográfica $(\mathrm{FFO})(\mathrm{t}(22)=3,02, \mathrm{p}<, 01)$ e o efeito de identidade interlinguística (II) ( $\mathrm{t}(22)=2,84, \mathrm{p}<, 01$ ), o mesmo não ocorrendo junto ao efeito de interferência semântica (IS).

Outra evidência observada na figura é que as palavras cognatas foram nomeadas mais rapidamente em todas as condições, seguidas pelas falso-cognatas, e pelas não-cognatas, respectivamente. As comparações entre os três tipos de palavras tiveram relevância estatística: entre cognatas e falso-cognatas ( $\mathrm{t}(22)=-8,79, \mathrm{p}<, 01)$; entre cognatas e não-cognatas $(\mathrm{t}(22)=-14,25, \mathrm{p}<, 01)$; e entrefalso-cognatas e não-cognatas $(\mathrm{t}(22)=-4,02$, $\mathrm{p}<, 01)$. O status cognato das palavras foi significativo estatisticamente $(\mathrm{F}(2,44)=88,60, \mathrm{MSE}=50010,29, \mathrm{p}<, 01)$, tanto isoladamente quanto na interação com os tipos de interferência $(F(4,88)=6,83$, MSE $=33784,99$, $\mathrm{p}<, 01)$. Nas comparações das médias no efeito de facilitação fonológica/ ortográfica (FFO) entre cognatas e falso-cognatas $(\mathrm{t}(22)=-7,41, \mathrm{p}<, 01)$ e entre cognatas e não-cognatas $(\mathrm{t}(22)=-7,22, \mathrm{p}<, 01)$, no efeito de identidade interlinguística (II) entre cognatas e falso-cognatas $(\mathrm{t}(22)=-8,94$, $\mathrm{p}<, 01)$, entre cognatas e não-cognatas $(\mathrm{t}(22)=-10,80, \mathrm{p}<, 01)$, e entre falso-cognatas e não-cognatas $(\mathrm{t}(22)=-3,71, \mathrm{p}<, 01)$; e, no efeito de interferência semântica (IS) entre cognatas e falso-cognatas $(\mathrm{t}(22)=-3,26$, $\mathrm{p}<, 01)$, entre cognatas e não-cognatas $(\mathrm{t}(22)=-6,50, \mathrm{p}<, 01)$, e entre falso-cognatas e não-cognatas $(\mathrm{t}(22)=-3,07, \mathrm{p}<, 01)$.

Os resultados mostram que houve significância estatística na maioria das comparações testadas. Isso só não ocorreu nos seguintes contextos: i) na comparação entre os tipos de interferência entre si; ii) na interação das médias de tempo de resposta entre os tipos de interferência e os tipos de condição de relação, no efeito de interferência semântica; iii) na comparação dos tempos de resposta no efeito de facilitação fonológica/ortográfica entre não-cognatas e falso-cognatas. Queremos salientar a constatação de ausência de significância estatística dos efeitos de interferência entre si, o que pode ser tomado como evidência de que ao julgar tais efeitos é importante levar em consideração o status 
cognato das palavras envolvidas. Isso é reforçado pelos resultados significativos do efeito cognato, tanto isoladamente quanto em interação com os outros efeitos de interferência testados no experimento.

Por outro lado, quanto aos diferentes efeitos de interferência testados, observou-se que no caso do efeito de interferência semântica a nomeação foi mais lenta na condição relacionada (em que a palavra distratora era da mesma categoria semântica do nome do desenho), mas não houve significância estatística. Essa lenta latência de nomeação pode ser justificada pela ativação de pelo menos dois itens lexicais (um correspondente ao nome do desenho na L2 e o outro à palavra distratora na L1), os quais compartilham relações semânticas e por isso competem para a seleção. Em outras palavras, a ocorrência de competição lexical retarda a nomeação. Entretanto, considerando-se o princípio de ativação espalhada (o qual prevê que várias palavras serão ativadas, tanto na L1 quanto na L2), essas evidências não nos permitem julgar se a competição ocorre entre itens lexicais na mesma língua ou em línguas diferentes. De acordo com Costa et.al. (1999), a competição lexical não seria entre as línguas, mas internamente entre itens lexicais na língua de resposta. Entretanto, segundo Costa, Navarrete \& La Heij (2006), vários pesquisadores tem questionado a noção de que a interferência semântica tenha todas as condições de revelar a competição lexical, e de que isso possa ter sua origem no nível em que as representações semânticas são selecionadas. Em vista disso, não temos evidência suficiente para avaliar adequadamente a competição lexical.

Quanto ao efeito de identidade interlinguística (quando a distratora corresponde à tradução do nome-alvo), como era esperado, a nomeação foi mais rápida na condição relacionada, o que reforça a ideia de que somente um dos léxicos é examinado (o da língua de resposta). Seguindo as ideias de Costa, Miozzo \& Caramazza (1999), acreditamos que o desenho provavelmente ativou os nós lexicais correspondentes na L1 e na L2, e a palavra distratora, por sua vez, enviou extra-ativação à representação semântica (pois corresponde à representação semântica do nome do desenho) e ativou os nós lexicais correspondentes na L1 e na L2. Em vista disso, o nó lexical da L2, que é requerido para a resposta, é duplamente ativado, e o da L1 acaba sendo neutralizado.

Organon, Porto Alegre, nº 51, julho-dezembro, 2011, p. 81-101 
Quanto ao efeito de facilitação fonológica/ortográfica (quando a distratora é uma palavra fonologicamente relacionadas com o nomealvo), observou-se que, também conforme o esperado, todos os tipos de palavras foram nomeados mais rapidamente na condição relacionada, porém a nomeação das cognatas foi a mais rápida de todas. Isso permite ponderar que o maior compartilhamento de segmentos fonológicos entre o nome do desenho e a distratora parece facilitar a nomeação. Por outro lado, a posição intermediária das falso-cognatas, em termos de rapidez de nomeação, pode ser tomada como evidência da existência de ativação fonológica bidirecional, vinda da tradução (palavra distratora) que não compartilha relação semântica com o nome do desenho (é o caso de hueso [osso] e oso [urso], explicitados no Quadro 2)

Em suma, os resultados descritos e discutidos até aqui parecem fortalecer os pressupostos da HSE e evidenciar que o mecanismo de seleção é específico na língua. Além disso, os mesmos apontam a necessidade de, ao se investigar o processo de lexicalização, levar em consideração, também, o importante papel do status cognato das palavras, nesse caso.

A Figura 3, a seguir, ilustra os resultados descritos acima. Nela é possível perceber a distinção no desempenho dos participantes, conforme o status cognato, principalmente entre as cognatas.

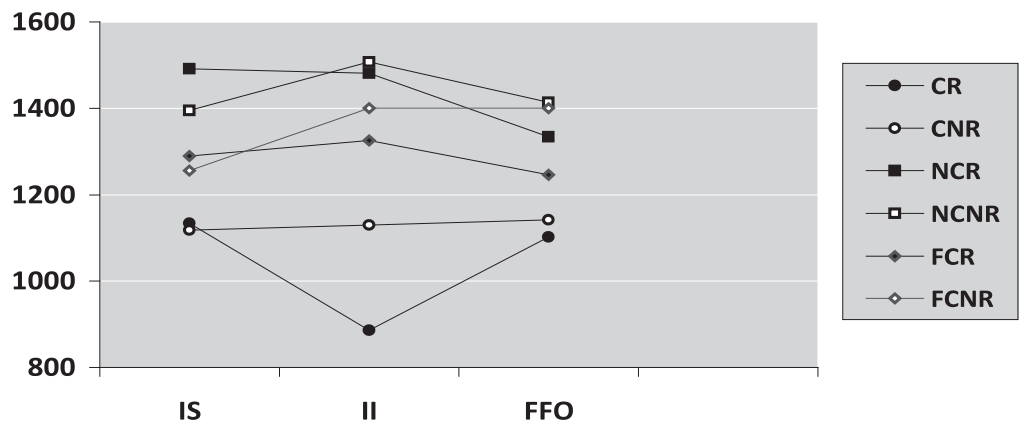

Figura 3: Média dos tempos de reação entre os diferentes efeitos de interferência e diferentes tipos de palavras, nas diferentes condições

Nota: $\mathrm{CR}=$ cognata relacionada; $\mathrm{CNR}=$ cognata não-relacionada; $\mathrm{NCR}=$ não-cognata relacionada; $\mathrm{NCNR}=$ não-cognata não-relacionada; $\mathrm{FCR}=$ falso-cognata relacionada; $\mathrm{FCNR}=$ falso-cognata não-relacionada; IS=interferência semântica; II=identidade interlinguística; $F F O=$ facilitação fonológica/ortográfica. 


\section{CONSIDERAÇÕES FINAIS}

Os resultados obtidos nos experimentos parecem evidenciar a especificidade do mecanismo de seleção, ou seja, reforçam a HSE (defendida por COSTA, MIOZZO \& CARAMAZZA, 1999, COSTA \& CARAMAZZA, 1999), tendo em vista que a nomeação foi mais rápida na condição relacionada nos contextos de efeitos de identidade e de facilitação fonológica/ortográfica e na condição não-relacionada nos contextos de efeitos de interferência semântica. Nesse sentido, a HSE é fortalecida, mas, desta vez, com bilíngues de línguas diferentes (português-espanhol) das que foram testadas por Costa e seus colegas (catalão-espanhol e espanhol-inglês).

Outra contribuição do nosso estudo refere-se à evidência do potencial do status cognato das palavras no processo de lexicalização. Uma vez que os tipos de palavras parecem ter influenciado na rapidez de nomeação, sendo que a cognatas sempre foram nomeadas mais rapidamente que as não-cognatas, e as falso-cognatas se mantiveram numa posição intermediária.

Porém, nosso estudo não nos permite avaliar adequadamente a presença de competição entre as línguas na produção de fala em geral, uma vez que o próprio desenho experimental exigia a co-ativação das duas línguas (nomeação na L2 e exposição a palavras na L1). Assim, embora tenhamos obtido resultados favorecendo a HSE, dessa vez com tipos de bilíngues e línguas diferentes, acreditamos que é preciso, ainda, uma análise mais extensiva e aprofundada para se chegar a conclusões mais confiáveis.

\section{BIBLIOGRAFIA}

BIALYSTOK, Ellen; CRAIK, Fergus I.M.; GREEN, David W.; GOLLAN, Tamar H. Bilingual Minds. Psychological Science. V. 10, (3). Association for Psychological Science, 2009, p. 89-129.

BIALYSTOK, Ellen; CRAIK, Fergus I.M.; KLEIN, Raymond; VISWANATHAN, Mythili. Bilingualism, aging, and cognitive control: evidence from the Simon task. Psychology and Aging. V. 19, (2). American Psychological Association, 2004, p. 290-303.

Organon, Porto Alegre, nº 51, julho-dezembro, 2011, p. 81-101 
BIALYSTOK, Ellen. Bilingualism in Development: language, literacy \& cognition. Cambridge: Cambridge University Press, 2001.

BUTLER, Yuko. G.; HAKUTA, Kenji. Bilingualism and second language acquisition. In: BHATIA, Tej K.; RITCHIE, William C. (Ed.). The Handbook of bilingualism. Oxford: Blackwell Publishing Ltd, 2006, p. 116-117.

BRIAN, Nicolás; BROVETTO, Claudia; GEYMONAT, Javier. Una experiencia de educación bilingue español-portugués en escuelas de la zona fronteriza. In.: BRIAN, Nicolás; BROVETTO, Claudia; GEYMONAT, Javier. (Orgs.). Portugués del Uruguay y educación bilingüe. Montevideo: ANEP-CEP, 2007. p. 9-48

COSTA, Albert. SALUD: El cerebro bilingue. El Confidencial, 24/03/2010. Entrevista concedida a Ana I. Gracia. Disponível em http://www.elconfidencial.com/salud/albert-costa-cerebro-bilingues20100324.html Acesso em: 10/01/2011.

COSTA, Albert; HERNÁNDEZ, Mireia; COSTA-FAIDELLA, Jordi; SEBASTIÁN-GALLÉS, Nuria. On the bilingual advantage in conflict processing: Now you see it, now you don't. Cognition. V. 113. Elsevier Science B.V. 2009. p. 135-149. COSTA. Albert; ALBAREDA, Bárbara; SANTESTEBAN, Mikel. Assessing the presence of lexical competition across languages: Evidence from the Stroop task. Bilingualism: Language and Cognition. 11, (1). Cambridge: Cambridge University Press, 2008. p. 121-131.

COSTA, Albert; HERNÁNDEZ, Mireia; SEBASTIÁN-GALLÉS, Nuria. Bilingualism aids conflict resolution: evidence from the ANT task. Cognition. V. 106. Elsevier Science B.V. 2008. p. 59-86.

COSTA, Albert. Speech Production in Bilinguals. In: BHATIA, Tej K.; RITCHIE, William C. (Ed.). The Handbook of bilingualism. Oxford: Blackwell Publishing Ltd, 2006, p. 201-223.

COSTA, Albert; LA HEIJ, Wido; NAVARRETE, Eduardo. The dynamics of bilingual lexical access. Bilingualism: Language and Cognition. 9, (2). Cambridge: Cambridge University Press, 2006. p. 137-151. COSTA, Albert; SANTESTEBAN, Mikel; IVANOVA, Iva. How do highly proficient bilinguals control their lexicalization process? Inhibitory and language-specific selection mechanisms are both functional. Journal of Experimental Psychology: learning, memory and cognition, v.32, (5). American Psychological Association. 2006, p. 1057-1074. 
COSTA, Albert. Lexical Access in Bilingual Production. In: KROLL, Judith F. DE GROOT, Annette M.B. (Ed.). Handbook of bilingualism: Psycholinguistic Approaches. Oxford: Oxford University Press, 2005, p. 308-325.

COSTA, Albert; SANTESTEBAN, Mikel; CAÑO, Agnès. On the facilitatory effects of cognate words in bilingual speech production. Brian and Language. V.94, 2005, p.94-103.

COSTA, Albert; SANTESTEBAN, Mikel. Lexical access in bilingual speech production: Evidence from language switching in highly proficient bilinguals and L2 learners. Journal of Memory and Language, v.50, 2004, p.491-511.

COSTA, Albert; SANTESTEBAN, Mikel. Bilingual word perception and production: two sides of the same coin? TRENDS in cognitive sciences. V. 8, (6). Science direct. 2004, p. 253.

COSTA, Albert; COLOMÉ, Àngels; GÓMEZ, Olga; SEBASTIÁNGALLÉS, Nuria. Another look at cross-language competition in bilingual speech production: lexical and phonological factors. Bilingualism: Language and Cognition. 6, (3). Cambridge: Cambridge University Press, 2003. p. 167-179. COSTA, Albert; CARAMAZZA, Alfonso; SEBASTIÁN-GALLÉS, Nuria. The cognate facilitation effect: Implications for models of lexical Access. Journal of Experimental Psychology: Learning, Memory and Cognition. V. 26, (5), 2000, p. 1283-1296.

COSTA, Albert; COLOMÉ, Àngels; CARAMAZZA, Alfonso. Lexical access in speech production: the bilingual case. Psicológica, 21, (2) 2000, p. 403-437.

COSTA, Albert; CARAMAZZA, Alfonso. The semantic interference effect in the picture-word interference paradigm: does the response set matter? Cognition. V. 75. Elsevier Science B.V. 2000. p. B51-B64. COSTA, Albert; CARAMAZZA, Alfonso. Is lexical selection in bilingual speech production language-specific? Further evidence from Spanish-English and English-Spanish bilinguals. Bilingualism: Language and Cognition. 2, (3). Cambridge: Cambridge University Press, 1999. p. 231-244.

COSTA, Albert; MIOZZO, Michele; CARAMAZZA, Alfonso. Lexical selection in bilinguals: Do words in the bilingual's two lexicons compete for selection? Journal of Memory and Language. 41. 1999, p. 365-397.

Organon, Porto Alegre, no 51, julho-dezembro, 2011, p. 81-101 
CRAIK, Fergus I.M.; BIALYSTOK, Ellen. Cognition Through the lifespan: mechanisms of change. TRENDS in cognitive sciences. V. 10, (3). Science direct. 2006, p. 131-138.

DE BOT, Kees. A bilingual production model: Levelt's speaking' model adapted. Applied Linguistics. V. 13, (1). Oxford: Oxford University Press, 1992, p. 1-24.

GASS, Susan; SELINKER, Larry. Second language acquisition: An introductory course. $3^{\mathrm{a}} \mathrm{ed}$. New York: Routledge: 2008.

GREEN, David. W. Mental control of the bilingual lexico-semantic system. Bilingualism: Language and Cognition. 1, (2). Cambridge: Cambridge University Press, 1998, p. 67-81.

. Control, activation, and resource: A framework and a model for the control of speech in Bilinguals. Brain and Language. 27. Academic Press, 1986, p. 210-223

GROSJEAN, François. Studying bilinguals: methodological and conceptual issues. In: BHATIA, Tej K.; RITCHIE, William C. (Ed.). The Handbook of bilingualism. Oxford: Blackwell Publishing Ltd, 2006, p. 32-63. . Transfer and language mode. Bilingualism: Language and Cognition, 1, 1998, p. 175-176.

HERMANS, Daan. Between-language identity effects in picture-word interference tasks: A challenge for language-nonspecific or languagespecific models of lexical access? International Journal of Bilingualism. V. 8, (2), 2004, p. 115-125.

HERMANS, Daan; BONGAERTS, Theo; DE BOT, Kees; SCHREUDER, Robert. Producing words in a foreign language: can speakers prevent interference from their first language? Bilingualism: Language and Cognition. V.1, (3). Cambridge: Cambridge University Press. 1998, p. 213-230. LEVELT, Willem J.M. Spoken word production: A theory of lexical access. PNAS, V.98, $\mathrm{n}^{\circ} 23$. Stanford: Stanford University's Highwire Press, 2001, p. 13464-13471.

LEVELT, Willem. J. M. Speaking: From intention to articulation. Cambridge, MA: Bradford/MIT Press. 1989.

MAHON, Bradford Z. COSTA, Albert; PETERSON, Robin; VARGAS, Kimberly A. CARAMAZZA, Alfonso. Lexical selection is not by competition: a reinterpretation of semantic interference and facilitation effects in the picture-word interference paradigm. Journal of Experimental Psychology: Learning, Memory and Cognition. V. 33, (3), 2007, p. 503-535. 
MCLAUGHLIN, Barry. Restructuring. Applied Linguistics. V.11, (2). Oxford: Oxford University Press, 1990, p. 113-128.

POULISSE, Nanda; BONGAERTS, Theo. First language use in second language production. Applied Linguistics. V.15, (1). Oxford: Oxford University Press, 1994, p. 36-57.

POULISSE, Nanda. Language production in bilinguals. In DE GROOT, A. M. B.; KROLL, J. K. (Eds.), Tutorials in bilingualism: Psycholinguistic perspectives. Mahwah, NJ: Lawrence Erlbaum, 1997, p. 201-225.

ROELOFS, Ardi. Lemma selection without inhibition of languages in bilingual speakers. Bilingualism: Language and Cognition, 1998, p. 94-95

SÁNCHEZ CASAS, R. M.; DAVIS, C. W.; GARCÍA ALBEA, J. E. Bilingual lexical processing: Exploring the cognate/noncognate distinction. European Journal of Cognitive Psychology, v.4, 1992, p. 293-310. 